\title{
Análise da interação proteica na evolução do câncer
}

\author{
Analysis of Protein Interaction in the Cancer Development \\ L. H. Rauber ${ }^{*}$; C. A. Bugs ${ }^{2}$; E. M. Simão ${ }^{1}$ \\ ${ }^{I}$ Programa de Pós Graduação em Nanociências, Centro Universitário Franciscano, \\ CEP 97010-491, Santa Maria-RS, Brasil \\ ${ }^{2}$ Universidade Federal do Pampa, CEP 97300-000, São Gabriel-RS, Brasil: \\ *luiz.rauber@gmail.com \\ (Recebido em 24 de julho de 2015; aceito em 09 de novembro de 2015)
}

\begin{abstract}
A ativação das vias dos mecanismos de manutenção do genoma (MMG), tais como: ciclo celular (CC), resposta ao dano no DNA (RDD) e apoptose (APO), contribuem significativamente para o desenvolvimento tumoral. Em estudos anteriores, foram verificados em processos pré-cancerosos a ativação de uma barreira anti-câncer, que é responsável pela prevenção da progressão tumoral. A identificação dos genes expressos durante a ativação da barreira anti-câncer, associadas com as interações nas vias MMG, tornam-se uma complementariedade ao estudo da evolução do câncer. Neste trabalho, o objetivo foi investigar a ativação dos genes das vias MMG em pré-câncer da glândula adrenal, cólon, pâncreas e folículos da tireoide, usando redes de interação entre proteínas. Para descrever este estudo foi proposta a modelagem das redes de interação entre as proteínas das vias MMG usando o software Cytoscape. Os resultados obtidos com os genes destacados em expressão e quantidade de interações foram comparados com os resultados de publicações anteriores e reconfirmaram a relevância dos genes CDKN1A, CHEK1, ATR, TP53, MRE11A e XRCC4. A análise por vias permitiu a identificação de outros genes complementares aos trabalhos anteriores, como os genes SKP2, CCNO, FADD, RAD50, NBN, $B I R C 3, C D K 2$ e XRCC6. Estes genes estão associados e complementam os estudos sobre a ativação da barreira anti-câncer. Estas considerações realçam a importância de observar todo o contexto biológico sistêmico e imersivo.
\end{abstract}

Palavras-chave: bioinformática, expressão gênica, barreira anti-câncer

The activation of genome maintenance mechanisms (MMG) pathways such as: cell cycle (CC), DNA damage response (DDR) and apoptosis (APO) significantly contribute to tumor development. In previous studies, it was found in pre-cancerous process there is activation of an anti-cancer barrier, which is responsible for prevention of tumor progression. The identification of the genes expressed during activation of the anti-cancer barrier, associated with the interactions in MMG pathways, becomes a complementarity to the study of the cancer development. In this work, the objective was to investigate the activation of the genes in the MMG pathways in pre-cancer of the adrenal gland, colon, pancreas and thyroid follicles, using networks of interaction between proteins. To describe this study was proposed the modeling interaction networks between the proteins of MMG pathways using the Cytoscape software. The results obtained with the most prominent genes in expression and quantity of interactions were compared with the results of previous publications and reconfirmed the relevance of CDKNIA, CHEKI, ATR, TP53, MRE11A and XRCC4 genes. This analysis allowed the identification of other genes complementary to previous studies as SKP2, CCNO, FADD, RAD5O, NBN, BIRC3, CDK2 and XRCC6 genes. These genes are associated and complement the studies on the activation of anti-cancer barrier. These considerations highlight that it is important to note the entire biological systemic and immersive context

Keywords: bioinformatics, gene expression, anti-cancer barrier 


\section{INTRODUÇÃO}

A representação por redes de interação proteína-proteína e a análise da expressão gênica são fatores mensuráveis em ferramentas usuais em bioinformática, como o software Cytoscape $[1,2,3]$. Com a utilização de grafos pode-se facilitar a visualização e elevar a confiança sobre os resultados, pois torna mais prática a análise quantitativa e qualitativa, o monitoramento, a avaliação e o controle sobre as interações proteicas. Os grafos ainda contribuem para o uso de algoritmos na busca de padrões em redes complexas, como a expressividade proteica de forma visual $[4,5,6]$.

Redes de interações proteicas são caracterizadas pela interação entre várias proteínas, que juntas executam tarefas no organismo através de vias de sinalização celular. Estas vias definem e realizam funções, como garantir a estabilidade do genoma pela ativação das vias dos mecanismos de manutenção do genoma (MMG) [6].

As vias MMG reagem a danos que causam alterações no ácido desoxirribonucleico (DNA). Quando há um dano, consequentemente, há uma reação em cadeia que provocará a ativação de diversas vias MMG. Se estes danos não forem corrigidos, poderá ocorrer uma proliferação desordenada de células e o desenvolvimento de um tumor maligno. A instabilidade celular é uma das características já identificadas em diferentes tipos de tumores. O surgimento e evolução neste tipo de doença ocorre de acordo com fatores ambientais e genéticos ainda não controlados, sendo exemplos desses fatores a radiação e a hereditariedade $[7,8,9]$.

Na evolução do câncer, há a ativação e inibição de algumas vias MMG que atuam para evitar, reparar ou parar a instabilidade celular. Entre as principais vias observam-se as responsáveis pela inibição e ativação do ciclo celular (CC), resposta ao dano no DNA (RDD) e a ativação da apoptose (APO) $[8,10,11]$.

Uma das formas utilizadas para analisar esta ativação ou inibição das vias é através da expressividade gênica. Quando o gene torna-se expresso, é sinal que ele está codificando uma proteína, assim interagindo na ativação ou desativação de outros genes em sua via, fazendo com que ocorra uma série de novas interações proteicas. A mensuração da expressão gênica, ocorre por meio de técnicas como os microarranjos produzidos pela Affymetrix GeneChip. A técnica de microarranjos envolve a comparação de transcritos de células com sequências de DNA em um chip contendo um oligonucleotídeo. Este é um processo que pode ser aplicado em inúmeras análises biológicas, como em estudos da barreira anti-câncer [10].

A evolução do câncer foi abordada em modelos que descrevem as principais vias MMG que são inibidas e ativadas nos processos pré-cancerosos e cancerosos, e seus genes mais expressos nestas vias. Nestes modelos, observou-se que há a ativação de uma barreira anti-câncer provocada pela ativação da RDD e da APO. A ativação desta barreira ocorre em tecidos précancerosos e impede a progressão dos danos [10,12].

Nas vias MMG expressas em tecidos pré-canceros não há uma análise sobre as interações proteicas. Esta representação tem relevância, uma vez que, as interações associadas com a expressão gênica, mostram os principais genes e grupos funcionais de proteínas expressas durante a ativação da barreira anti-câncer.

$\mathrm{O}$ objetivo deste trabalho é estudar a interação proteica de proteínas pertencentes às vias MMG na barreira anti-câncer, identificando-se alguns genes que tenham destaque por expressão ou interação. A identificação destes genes possibilita o desenvolvimento de tratamentos otimizados e mais eficazes para o combate e monitoramento de tumores e outras doenças[13,14,15].

\section{MATERIAL E MÉTODOS}

\subsection{VIAS MMG}

Para o desenvolvimento deste trabalho foram usadas vias MMG publicadas no material suplementar do artigo de Simão e colaboradores, publicado em 2012 [10]. Do trabalho realizado por Simão e colaboradores foram selecionadas as vias MMG com maior expressão em (ver 
tabela 1) nos adenocarcinomas e adenomas da glândula adrenal, cólon, pâncreas e foliculares da tireoide [10].

Tabela 1: Vias MMG. Na primeira coluna, estão listadas as vias e na segunda coluna os números de genes pertencentes nessas vias. A terceira coluna indica o símbolo representativo da via. Fonte: Adaptado de Simão e colaboradores [10].

\begin{tabular}{c|c|c}
\hline \multicolumn{2}{c}{ Vias de ciclo celular $(\mathbf{C C})$} \\
\hline Vias & Número de Genes & Símbolo da via \\
\hline Ponto de verificação G1/S & 21 & $\mathrm{G} 1 / \mathrm{S}$ \\
\hline Ponto de verificação da fase mitótica G2/M & 43 & $\mathrm{G} 2 / \mathrm{M}$ \\
\hline Fase mitótica M-M/G1 & 178 & $\mathrm{M}-\mathrm{M} / \mathrm{G} 1$ \\
\hline$R B / \mathrm{E} 2 \mathrm{~F}-$ Via de retinoblastoma do fator transcrição E2F & 78 & $R B / \mathrm{E} 2 \mathrm{~F}$ \\
\hline
\end{tabular}

Vias de resposta ao dano no DNA (RDD)

\begin{tabular}{c|c|c}
\hline Vias & Número de Genes & Símbolo da via \\
\hline Reparo por excisão de bases & 44 & BER \\
\hline Recombinação homóloga & 34 & HR \\
\hline Reparo por recombinação não homóloga & 14 & NHEJ \\
\hline Reparo da quebra da fita dupla & 22 & DSBR \\
\hline
\end{tabular}

Vias de apoptose (APO)

\begin{tabular}{c|c|c}
\hline Vias & Número de Genes & Símbolo da via \\
\hline Sinalização de receptor de fator de necrose tumoral 1 & 13 & TNFR1 \\
\hline Sinalização de receptor de fator de necrose tumoral 2 & 10 & TNFR2 \\
\hline Apoptose no Homo Sapiens & 83 & APO \\
\hline Ativação do fator nuclear kappa-beta & 20 & NFKB \\
\hline Senescência replicativa & 56 & SR \\
\hline
\end{tabular}

\subsection{BANCO DE DADOS STRING - IDENTIFICAÇÕES PROTEICAS}

Foi utilizado o banco de dados String- $D B$ para buscar a interação entre as proteínas, com base nas informações das vias MMG citadas na tabela 1. As proteínas foram inseridas no banco de dados através do seu símbolo aprovado (AppSymbol), cujo identificador está disponível na ontologia Ontocancro.

As redes de interação para cada via foram obtidas mantendo-se alguns critérios, tais como: a busca por interações de co-expressão, bancos de dados e experimentos. Foi escolhido a pontuação de confidência de 0,700 [16].

\subsection{AMOSTRAS DE MICROARRANJOS}

O Gene Expression Omnibus (GEO) é um banco de dados que armazena informações de expressão gênica. Foram obtidos conjuntos de amostras de expressão gênica de adenomas produzidos pelos microarranjos da Affymetrix Gene Chip. As plataformas gênicas escolhidas foram a GPL570 com aproximadamente 33.000 genes, e a GPL96 com aproximadamente 20.000 genes. Todas as amostras foram normalizadas segundo o protocolo de normalização das médias robustas para múltiplos chips (RMA), que utiliza o logaritmo na base dois como meio normalizador [16].

As amostras de microarranjos utilizados nesse trabalho estão listadas de acordo com o identificador no banco de dados GEO: 
- GSE4183: cólon retal, contendo: 8 amostras controle (normal) e 15 com adenoma (précâncer) [17];

- GSE10927: glândula suprarrenal (adrenal), contendo: 10 amostras de controle e 22 de adenoma [18];

- GSE19650: pâncreas, contendo 7 amostras normais do ducto pancreático e 6 de adenoma mucinoso papilar intraductal [19];

- GSE27155: foliculares de tireoide, contendo 4 amostras normais e 17 de adenoma [20];

As amostras extraídas do GEO, para cada doença, foram agrupadas por média aritmética em três grupos de expressão gênica: um grupo normal e um grupo adenoma. Os grupos foram estudados utilizando-se a análise estatística da mudança de expressão (ME). O cálculo da ME, para cada gene de uma via é usado em grandes conjuntos de amostras que têm diferenças exponenciais entre a expressão dos genes presentes nos microarranjos [10,21]. O método se baseia na razão da expressão de cada gene " $x$ " de uma via com tamanho " $i$ " entre as amostras experimentais (grupo adenoma $\left(\mathrm{n}_{2}\right)$ ) e as amostras controle (grupos normal $\left(\mathrm{n}_{1}\right)$ ).

$$
\mathrm{ME}_{i}=\frac{x_{i}\left(n_{2}\right)}{x_{i}\left(n_{1}\right)}(1)
$$

Uma vez calculada a ME, observa-se o valor da mudança de expressão para cada gene em uma via. Se os valores estão próximos de 1 não há mudança de expressão. Porém, se os valores variarem, para ME > 1 há mudança de expressão nas amostras experimentais (grupo adenoma $\left(\mathrm{n}_{2}\right)$ ), e para $\mathrm{ME}<1$ há mudança de expressão nas amostras controle (grupos normal $\left.\left(\mathrm{n}_{1}\right)\right)$ [21].

\subsection{MODELAGEM DAS VIAS COM DADOS DA MUDANÇA DE EXPRESSÃO}

O software Cytoscape é utilizado para a modelagem, visualização e análise de redes de interação molecular, por exemplo, das vias MMG. O software foi originalmente desenvolvido para a pesquisa biológica, mas atualmente é uma plataforma geral para análise de redes complexas, podendo ter acréscimo de recursos adicionais por meio de aplicativos [9].

Inicialmente foram importadas para o software Cytoscape as redes de interação entre as proteínas para cada via MMG da tabela 1. Após, utilizando-se a ferramenta de importação de expressão dos genes, foram importados os valores de ME das doenças extraídas do GEO, fazendo a relação gene versus nó (nodo) através do nome aprovado do gene.

O software permitiu que fossem aplicadas cores aos nós em cada grafo. Assim, os nós variaram de verde a vermelho conforme o gradiente de cores da figura 1a. Quanto mais próxima da cor vermelha, maior foi a expressão de acordo com a ME. Outro recurso visual empregado foi a variação do tamanho dos nodos da mesma forma que a cor, quanto maior o nodo e a fonte da nomenclatura, maior a mudança de expressão (figura 1b) [22].

a)

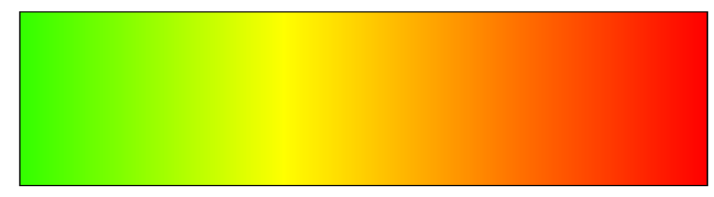

b)

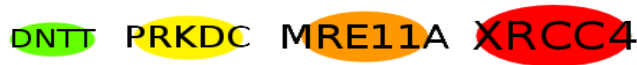

Figura 1: Recurso visual da variação de cor (a) e tamanhos (b) para demostrar o aumento da expressão gênica. 


\section{RESULTADOS E DISCUSSÃO}

De todos os resultados encontrados, destacaram-se nove vias MMG, expressas em adenoma, que apresentaram maior similaridade estatística, pelo cálculo da ME com os estudos relacionados barreira anti-câncer $[10,12]$.

\subsection{VIAS DE CICLO CELULAR (CC)}

\subsubsection{Via G1/S - Amostras de Adenoma do Cólon}

A via de sinalização do ponto de verificação G1/S combina o processo de verificação para a preparação da síntese celular dentro do ciclo. De acordo com a figura 2, os genes mais expressos e conectados em adenoma do cólon são: SKP2, TP53 e CDK2.

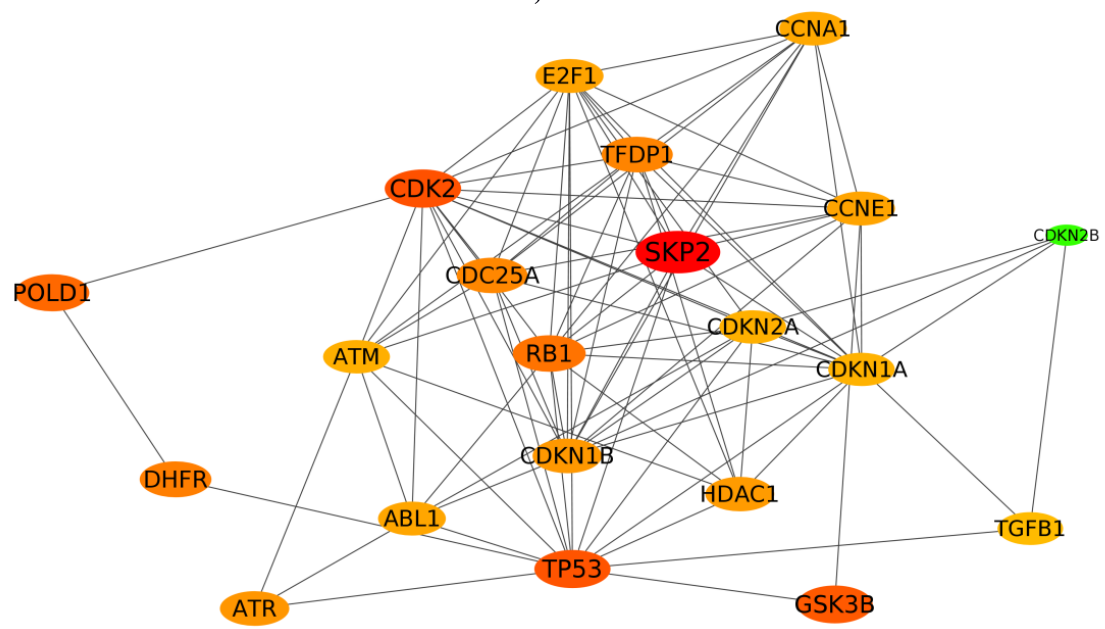

Figura 2: Via de G1/S com a mudança de expressão em relação a amostras de adenoma no cólon.

O gene SKP2 (ME de 1,18) é o mais diferencialmente expresso na via e está associado a vários tipos de câncer. Ela atua no complexo denominado ubiquitina ligases, que é uma classe de enzimas que regulam a progressão do ciclo celular. As mudanças na sua atividade podem contribuir para a proliferação de células malignas. A SKP2 também é responsável pela degradação de proteínas supressoras de tumor, tais como inibidores de ciclinas dependentes de quínase, como $p 21$ (CDKN1A) e p27 (CDKN1B), acelerando a progressão do ciclo celular e dos tumores [23]. O gene CDKNIA que interage com o $S K P 2$ teve uma diferença de 0,976 no ME em adenoma, conforme observado no gradiente de cores da figura 2. O transcrito do gene SKP2 está vinculado com a resistência à quimioterapia e radioterapia em tratamentos contra o câncer $[24,25]$.

O gene $G S K 3 B$ (ME de 1,078) é relevante devido as suas funções biológicas e atua na síntese do glicogênio, que é responsável por levar oxigênio para a célula, além de atuar em processos de desenvolvimento celular [26] e auxiliar na expressão de CDKNIA. A relação entre estas duas proteínas $(G S K 3 B$ e CDKNIA) estabelece que tratamentos de terapia gênica, com o uso de fármacos direcionados a $G S K 3 B$, em combinação com o tratamento por quimioterapia, poderiam representar uma estratégia terapêutica em tumores resistentes a este tipo de tratamento [27].

O gene ATR tem expressão em adenoma do cólon, o que está relacionado com a sua funcionalidade, pois o transcrito deste gene é uma quínase sensora de danos no DNA [28]. Este gene é essencial para regular e catalisar ações para frear ou reparar danos, principalmente na replicação celular. $\mathrm{O}$ gene $A T R$ é bastante expresso em vias MMG e está vinculado ao CC e $\operatorname{RDD}[29,30]$.

Na figura 2 também é observada a expressão do gene TP53 (ME de 1,085), que aparece conectada com os genes ATR, SKP2, CDKN1A e GSK3B, por exemplo. A TP53 está expressa quando identificado uma falha no DNA, e quando mutada está presente em $50 \%$ dos casos de 
câncer. Esse gene apresenta 14 conexões e possui ME semelhante aos genes CDKN1A e CDK2, lembrando que uma falha em um nodo muito conectado causa uma quebra em toda a rede [31]. Esta quebra poderia ser observada na presença de danos a TP53 (desativação), o que deixaria o gene $G S K 3 B$ praticamente isolado, tendo apenas ligação com o gene CDKN1A. Estudos biológicos comprovam esta afirmação, ou seja, GSK3B e CDKN1A são dependentes da expressão do TP53 [27,28].

\subsubsection{Via G2/M - Amostras de Adenoma da Tireoide}

A via de ponto de verificação da fase mitótica G2/M (figura 3) realiza o processo de verificação para a preparação da replicação celular dentro do ciclo. Dentre as amostras de foliculares da tireoide, o gene que mais se destacou pela sua expressão e conectividade foi o CDKN1A com valor de ME de 1,14, seguido do gene ATR.

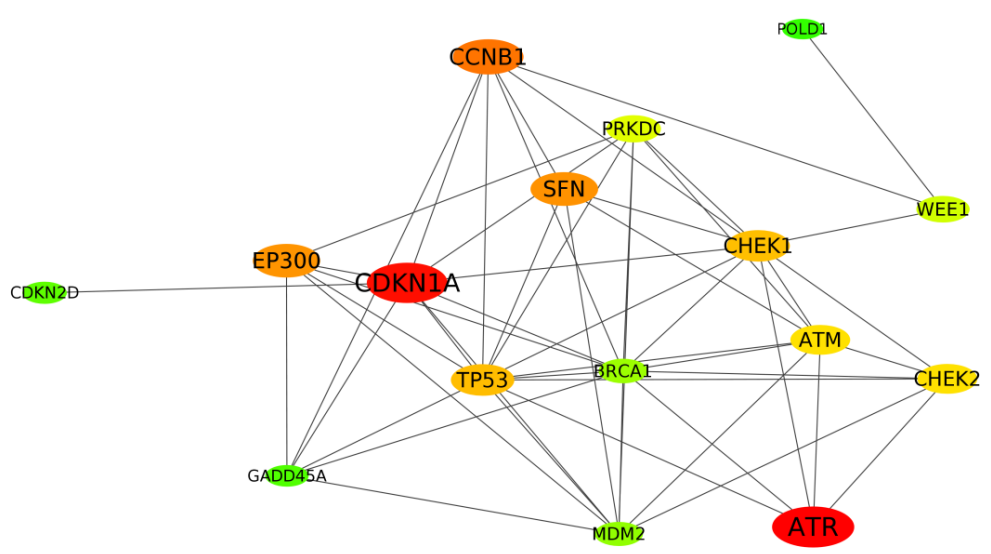

Figura 3: Via de G2/M com a mudança de expressão em relação as amostras de adenoma na tireoide.

A CDKN1A é a codificante da proteína $p 21$ [32], e por definição é uma ciclina dependente de inibidores de quínase. Atua no ciclo celular com atividades que mudam em resposta a sinais celulares. Elas fazem a fosforilação de proteínas específicas em intervalos precisamente cronometrados, controlando as atividades metabólicas da célula e assim tornando a divisão celular ordenada. A expressão de CDKNIA é controlada pela $p 53$, e na identificação de danos a p21 ocasiona a parada do ciclo celular na fase G1[33]. Alguns estudos relacionam a supressão da $C D K N 1 A$ com a supressão tumoral $[32,33,34]$.

As proteínas atr e p21 não interagem diretamente, mas existem algumas proteínas que interagem com ambas como é o caso do gene CHEK1. Este gene é um supressor do CDKN1A quando ocorrem danos no DNA. A CHEK1 também ativa o gene ATR, na fase G2 e também na fase $\mathrm{S}$ do CC [35]. A atr faz a ativação de outra proteína que está interligada com CDKN1A, a $T P 53$, como consequência, estimula a síntese da $p 21$, que contribui para a ativação da apoptose e senescência [24,28].

Destaca-se também nesta via o gene CCNB1. Este gene é reconhecido como uma ciclina biomarcadora, ou seja, se expressa na presença de neoplasia [36]. Os genes CDKN1A e ATR continuam tendo alta expressão na fase adenoma. Já a TP53 tem em adenoma maior expressão quando comparada ao carcinoma para a mesma doença. Isso caracteriza a ação do CC. Ela atua no RDD e bloqueia a expansão tumoral antes da proliferação de células defeituosas ocorrer.

\subsubsection{Via RB/E2F - Amostras de Adenoma do Cólon}

A via de retinoblastoma do fator de transcrição $E 2 F$ (RB/E2F) (figura 4) atua na fase de síntese $(\mathrm{S})$ do CC, onde a proteína inibidora de tumor retinoblastoma (RB) verifica se há falhas no DNA celular. A maior expressão foi do gene CHEK1 em adenoma (ME de 1,195) do cólon, assim como CDC6 (ME de 1,19)). 
$\mathrm{Na}$ via RB/E2F, CHEK1 está interligado com os genes CDC6 e CCNB1. O gene CDC6 atua para manter a regulação do ciclo celular, que é expressa em outros tipos de doenças, como nos tumores de mama [37]. O gene $C C N B 1$ pode ser usado como um biomarcador para doenças tumorais [36].

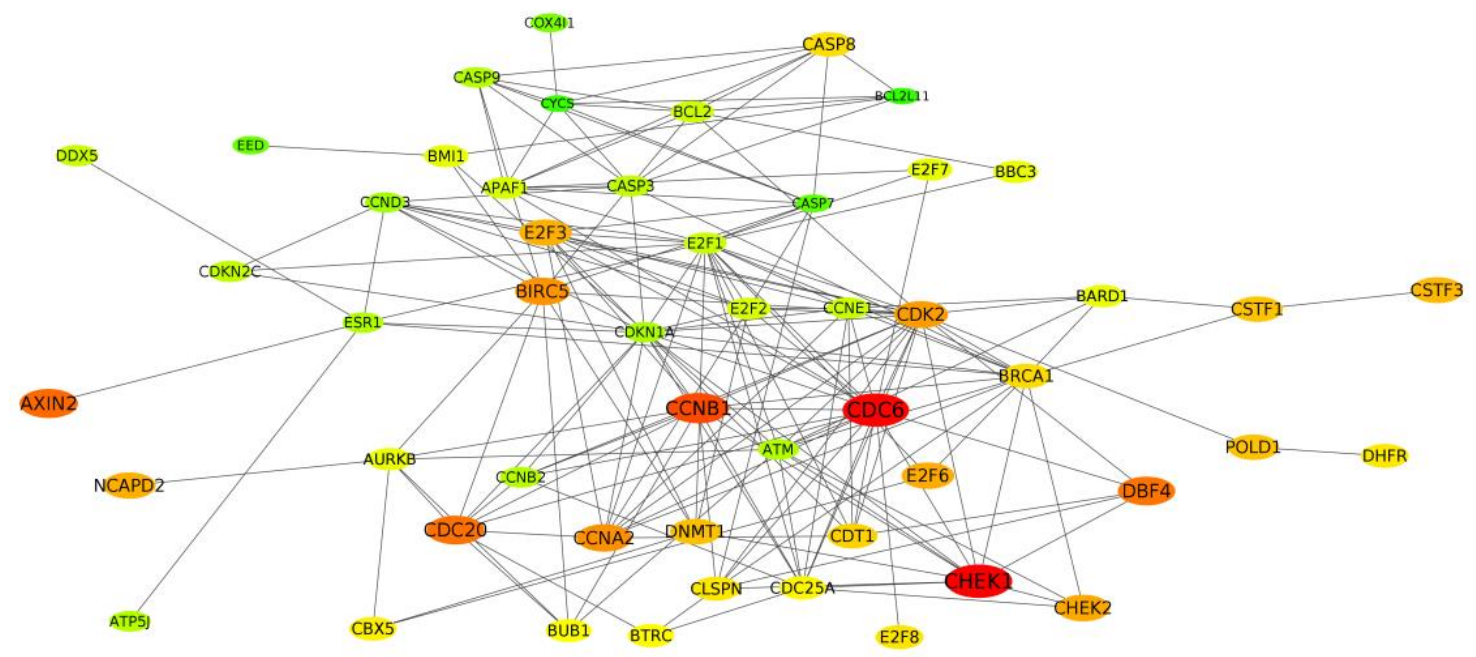

Figura 4: Via de RB/E2F com a mudança de expressão em relação as amostras de adenoma no cólon.

\subsection{VIAS DE RESPOSTA AO DANO DO DNA (RDD)}

\subsubsection{Via de Reparo por Excisão de Bases - Amostras de Adenoma do Cólon}

A via de reparo por excisão de bases (BER) corrige falhas na troca das bases nitrogenadas, que apresentarem disparidade na codificação do DNA. Embora tenha uma perda gradativa de função com o passar da idade, é um dos principais mecanismos de reparo do DNA [38]. A figura 5 representa a mudança de expressão em adenoma do cólon, com destaque para os genes FEN1, CCNO, MSH2 e POLE2.

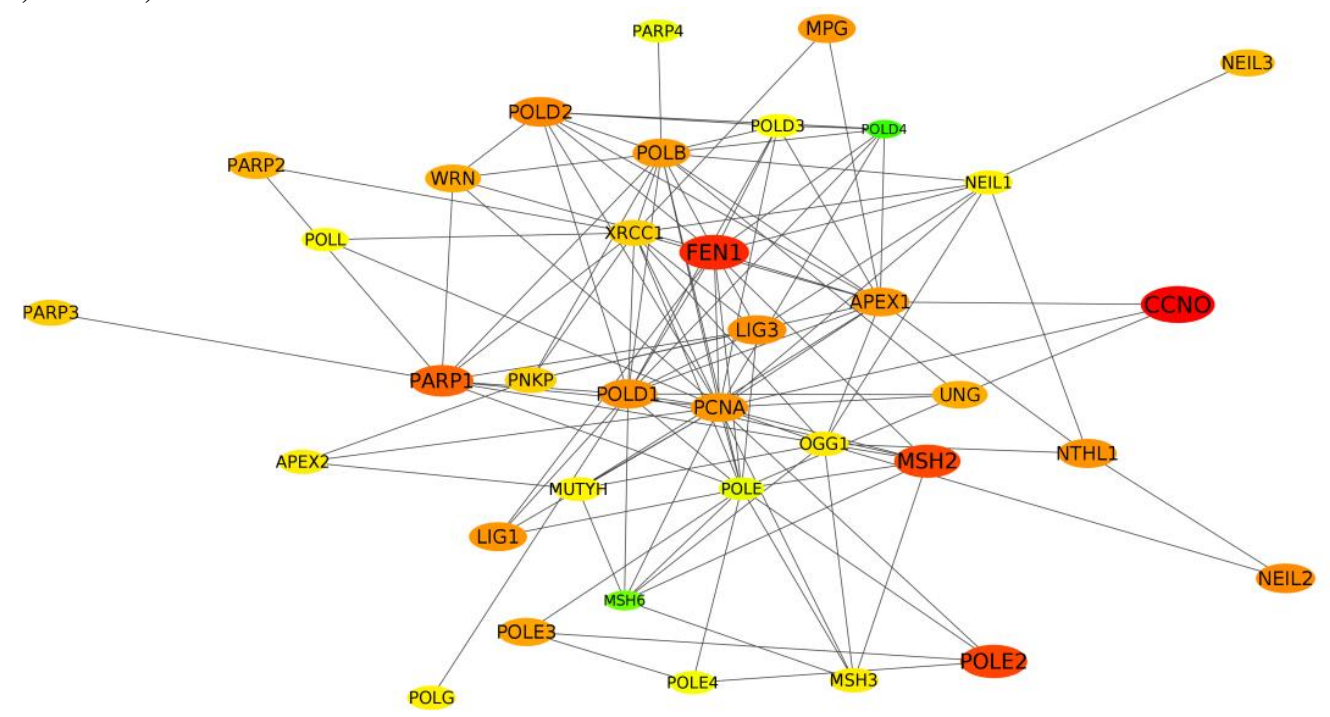

Figura 5: Via de BER com a mudança de expressão em relação as amostras de adenoma no cólon.

FEN1 é uma endonuclease que atua rompendo a fita de DNA nos terminais 5', essenciais para que a replicação seja isenta de falhas. É expressa quando um erro no DNA for identificado, e assim possa ocorrer a quebra da fita e a substituição da base [39]. 
O gene $C C N O$ é o codificador de uma proteína ciclina $\mathrm{O}$ e atua tanto na catálise de enzimas DNA glicosilases como na função como ciclina, onde colabora na ativação de reparo na presença de anormalidade no DNA, que resulta no câncer de cólon [38].

A POLE2 codifica uma polimerase, enquanto a FEN1 possibilita a segurança para que ocorra a ligação fosfodiéster corretamente entre as bases na cadeia de DNA. A POLE2 faz esta ligação de forma eficaz no DNA. O gene $M S H 2$ indica uma falha na fase S por uma mutação que atrapalha o fenótipo, e está hereditariamente relacionado ao câncer no cólon [38].

\subsubsection{Via de Reparo da Quebra da Fita Dupla - Amostras de Adenoma da Tireoide}

O reparo da quebra da fita dupla do DNA (DSBR) é uma das vias mais importantes que atuam na manutenção do genoma. A quebra em fitas duplas é um tipo de dano letal que exige uma coordenação entre os fatores que modulam a estrutura e a reparação do DNA [49]. Ela desencadeia a morte celular por inativação de genes. Na caracterização das vias DSBR, é fundamental decifrar as suas ligações com a tumorigênese para compreender a base do câncer e desenvolver terapias eficazes [40]. Nas amostras de foliculares da tireoide na fase adenoma (figura 6), destacam-se os genes expressos NBN, MDC1, XRCC4, TP53BP1, LIG4 e BRCA2.

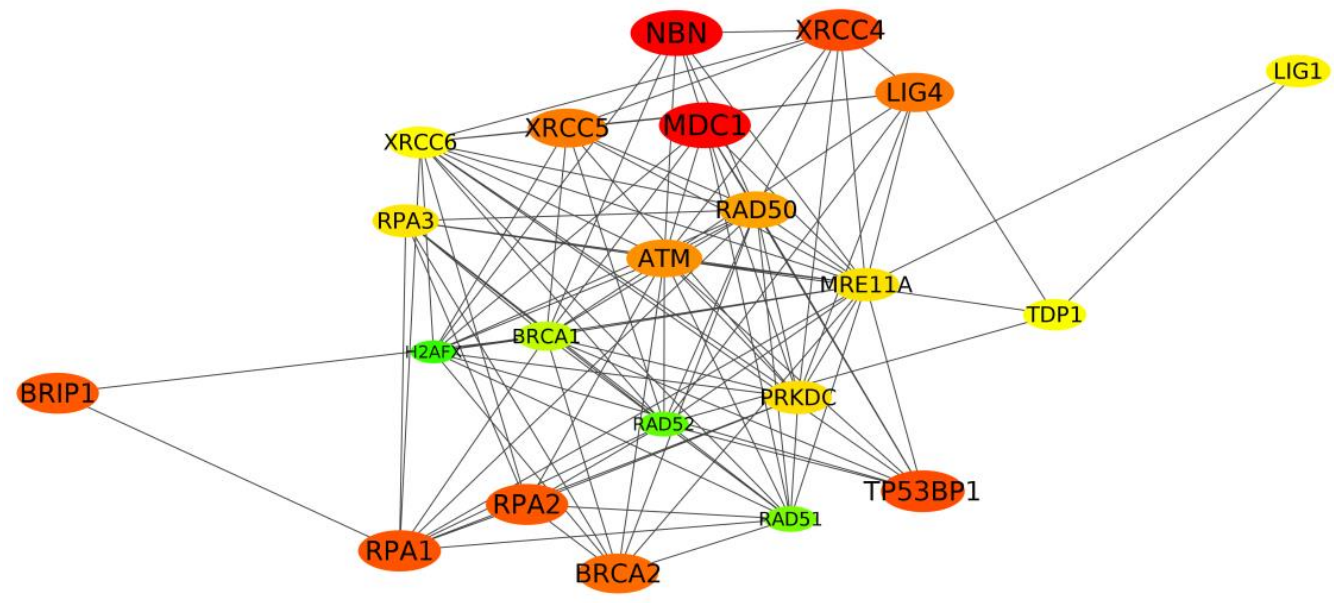

Figura 6: Via de DSBR com a mudança de expressão em relação a amostras de adenoma na tireoide.

O gene XRCC4 atua na manutenção geral da estabilidade do genoma, ligando-se a vias de reparo, como a NHEJ. Sua expressão alterada também pode indicar problemas em células e sugerem a presença de câncer [41]. Na figura 6 observa-se a sua ligação do XRCC4 com o LIG4. Ambos atuam na recombinação não homóloga, cobrindo o espaço (gap) resultado da reparação nas fitas do DNA com outra base por causa da eliminação de bases defeituosas. Posteriormente, ambas contribuem para a religação das fitas. O XRCC4 é ativador da LIG4, uma proteína do tipo ligase [42] com interação com a proteína $M D C 1$.

A $M D C 1$ interage diretamente com a $A T M$, e atuam na resposta celular a danos em cadeia dupla no DNA, mantendo a estabilidade genômica [43]. Mutações na ATM resultam em ataxiatelagectasia, uma desordem neurodegenerativa que caracteriza uma hipersensibilidade a raios ionizantes (agente carcinogênico). A ATM tem ação sobre a BRCA2 que se encontra destacada na presença de câncer de mama [42].

$N B N$ é um gene expresso para o reparo da quebra dupla e pertencente à família de outro gene na via DSBR, como o gene RAD50. Estudos recentes indicaram que mutações no gene $N B N$ reduzem o reparo do DNA e elevam a instabilidade cromossômica [44].

Na figura 6 observou-se, através da ligação com o gene RAD50, que há interação de $N B N$ com TP53BP1. Apesar de não ter uma ligação direta, ambos estão envolvidos com a falha no reparo do DNA. O TP53BP1 está diretamente envolvido com o desenvolvimento dos tumores [45].

De acordo com a figura 6, o gene que apresenta um maior número de interações é o $M D C 1$. Ele possui interação direta com o ATM, LIG4, NBN, RAD50, e indireta através da ATM com $B R C A 2$ e através da $N B N$ com XRCC4. Levando-se em consideração as mais expressas entre 
adenoma e adenocarcinoma, a RAD50 tem mais conexões. Uma das características da via DSBR é a expressão do gene $N B N$, que tem como principal potencialidade aumentar a expressão de MRE11 e RAD50 [44].

\subsubsection{Via de Reparo por Recombinação não Homóloga - Amostras de Adenoma do Pâncreas}

A via de reparo por recombinação não homóloga (NHEJ) é uma via complementar a via de reparo da quebra da fita dupla (DSBR) [46]. Com a análise envolvendo o adenoma do pâncreas (figura 7) foi identificado o gene XRCC4 com ME de 1,458.

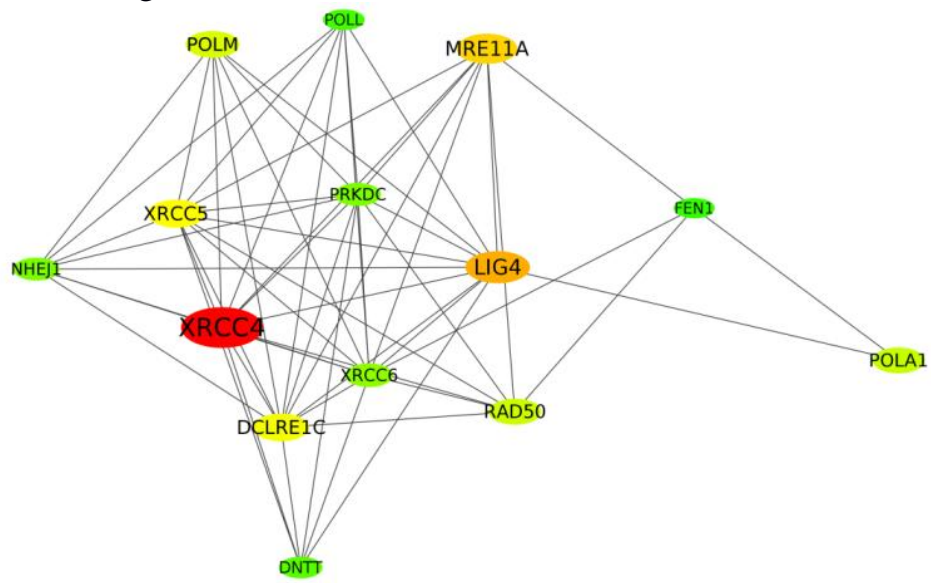

Figura 7: Via de NHEJ com a mudança de expressão em relação as amostras de adenoma no pâncreas.

O gene XRCC4 também apresenta a maior quantidade de interações com as outras proteínas da via. Este gene faz parte de uma subunidade (ligase IV) especializada em ações de correção na via NHEJ, com ações de fosforilação por ciclina dependente de quinase. Por este tipo de ação, alguns estudos feitos sobre o XRCC4 apontaram que a sua expressão previne a instabilidade genômica [47]. Cabe ressaltar também que XRCC4 depende de MRE11A, um gene que teve uma mudança de expressão relevante de adenoma para adenocarcinoma, com ME de 1,182 para 1,213 .

\subsection{VIAS DE APOPTOSE (APO)}

\subsubsection{Via da Ativação do Fator Nuclear kappa-Beta - Amostra de Adenoma Adrenal}

A ativação do fator nuclear kappa-beta $(N F K B)$ resulta em uma identificação para carcinomas. Assim, a inibição de $N F K B$ é considerada uma abordagem terapêutica promissora para bloquear o crescimento do tumor ou a sensibilização de células tumorais para as terapias mais convencionais, como a quimioterapia. Optou-se pela análise desta via com amostras da glândula suprarrenal (adrenal) pelo destaque da conectividade com os genes CHUK e ATM, conforme demonstrado na figura 8.

Os genes mais expressos da via são RAD50 (ME de 1,066) e XIAP (ME de 1,063), com expressão relevante de MRE11A. Os genes RAD50 e MRE11A já tiveram destaque na via DSBR.

O gene XIAP atua inibindo a apoptose. A sua expressão elevada inibe a apoptose extrínseca e intrínseca, já sua diminuição na expressão tem correlação com o controle da progressão tumoral e sensitividade a fármacos. Normalmente, ela não interfere na proliferação celular, mas aumenta a sensibilidade da necrose tumoral [45]. Nas vias com amostras de adrenal, o gene XIAP, tanto em fase adenoma quanto adenocarcinoma, teve aumento de expressão, o que sugere $o$ envolvimento deste gene com necrose [45]. 


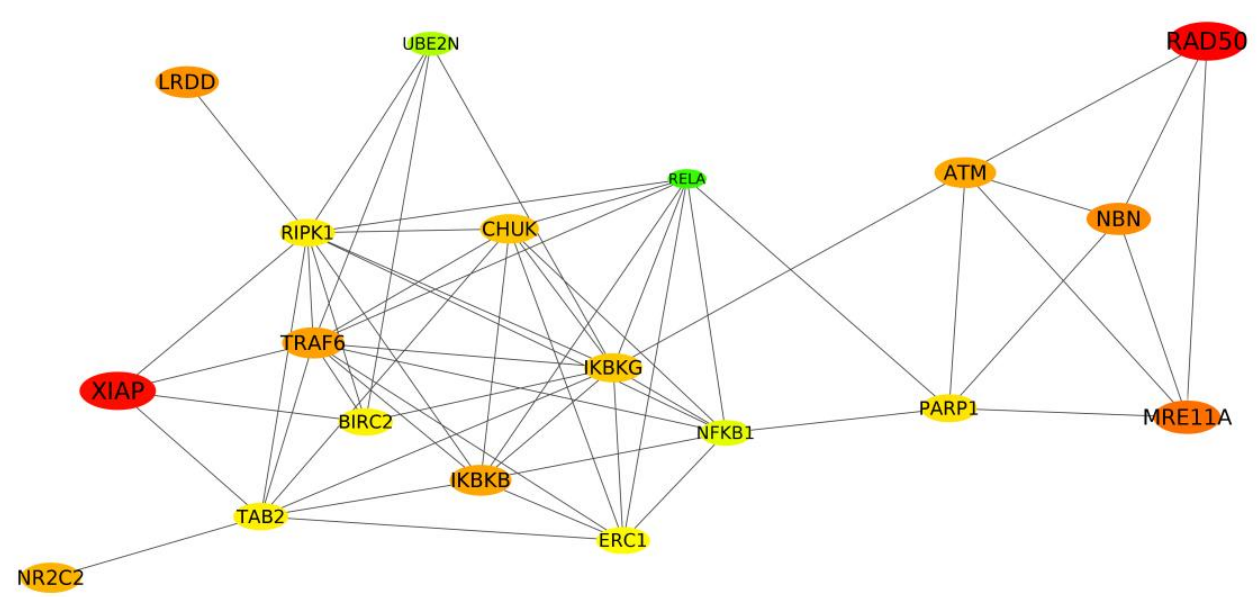

Figura 8: Via de NFKB com a mudança de expressão em relação as amostras de adenoma na adrenal.

\subsubsection{Via de Senescência Celular - Amostras de Adenoma Adrenal}

A senescência celular é a parada permanente do ciclo celular, um estado diretamente envolvido com o envelhecimento celular. Inicia por programação genética e envolve a deterioração dos telômeros e a ativação de genes supressores tumorais. Com isso, as células que entram em senescência param seus processos de reprodução após um determinado número de divisões celulares [48]. Para a análise desta via foram usadas amostras da glândula suprarrenal (adrenal), sendo os genes ATR, TP53 e CHEK1 destacados pela sua conectividade e expressão conforme demonstrado na figura 9.

Os genes ATR e TP53 já foram descritos na seção 3.1.1 sobre a via G1/S. Na via de SR esses dois genes são novamente os mais expressos na fase adenoma assim como foram na fase adenoma da G1/S. Também nesta via, há expressão relevante do gene $R A D 50$, que é uma subunidade chave do complexo $M R N$, que inclui também MRE11A e NBN. Este complexo é envolvido no processo de reparação das quebras duplas no DNA, formando uma ligação entre moléculas de DNA pela catalise das terminações quebradas [49]. Na figura 9 destaca-se as interações entre ATR, TP53 e RAD50.

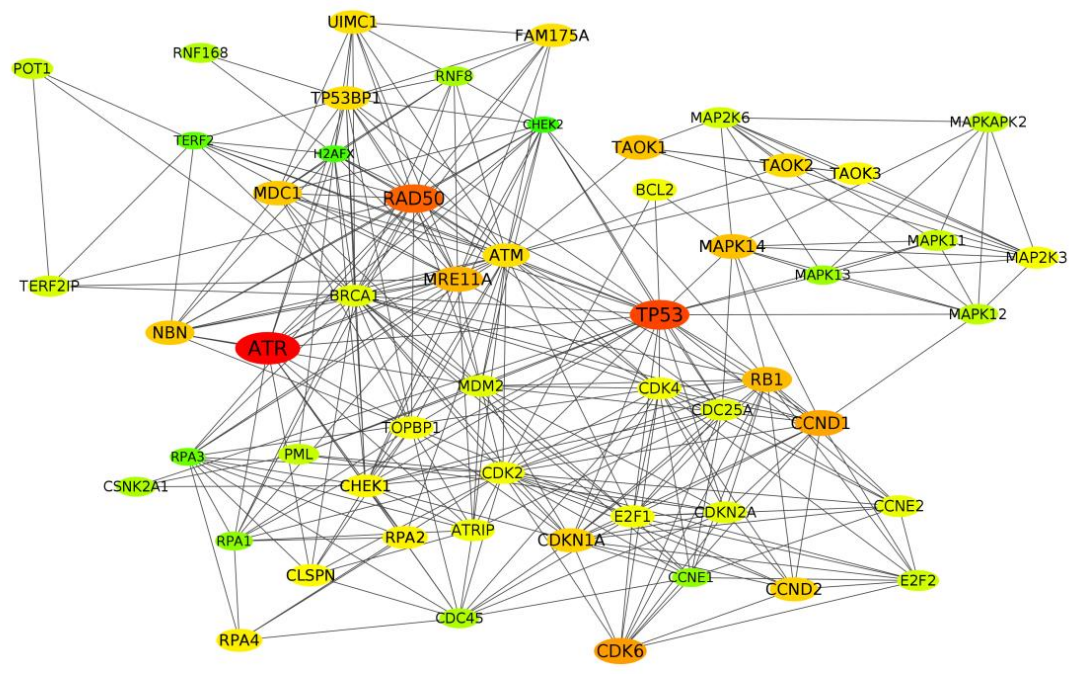

Figura 9: Via de SR com a mudança de expressão em relação as amostras de adenoma na adrenal.

\subsubsection{Via de Fator de Necrose Tumoral do Tipo 1 - Amostra de Adenoma do Pâncreas}

A via de fator de necrose tumoral do tipo 1 (TNFRl), que pertente ao conjunto de funções de ativação da apoptose, tem uma forte ligação com a expansão tumoral, pois está associada a angiogênese, em um processo que atua na ativação da necrose tumoral, evitando uma extensão 
do dano [50]. Neste sentido, há uma previsibilidade em relação a expressão de alguns genes da via. A quantidade de interações e a expressão dão destaques ao gene BIRC3.

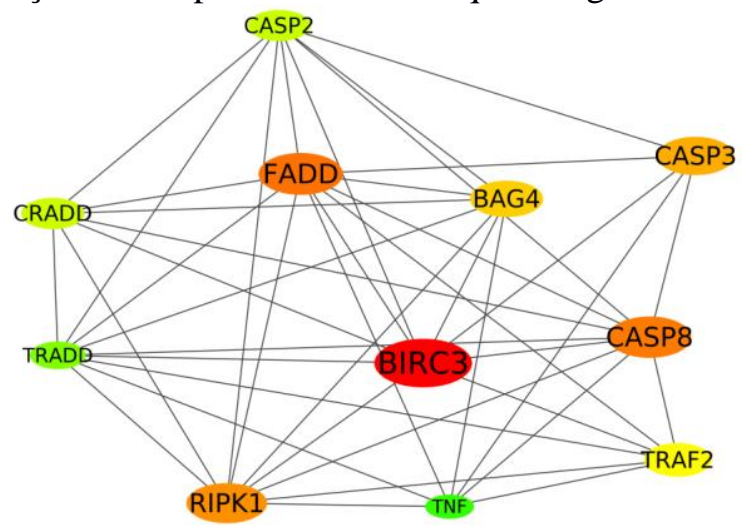

Figura 10: Via de TNFR1 com a mudança de expressão em relação as amostras de adenoma no pâncreas.

BIRC3 é um gene que atua inibindo a apoptose e expressando outros genes como o TRAF, que são desencadeadores da necrose e morte celular [51]. O controle da expressão do mesmo já foi estudado para a regulação da progressão tumoral de câncer cerebral, mama e gástrico [48].O gene $F A D D$ também teve destaque na via, por ser o gene com maior número de interações. Ele é parte do complexo RIPK1. Pela ligação com $C A S P 3$, que é conhecido pela execução de caspases para a apoptose, e também a ativação da necrose ao ativar a CASP8. A expressão da CASP3 potencializa a expressão de $C A S P 8$ e também de $F A D D$, o que pode suprimir a progressão tumoral, induzindo a necrose [51].

\subsection{PROTEÍNAS ALTERADAS NA BARREIRA ANTI-CÂNCER}

Nas vias de sinalização analisadas foram localizadas as proteínas mais expressas e as que apresentaram o maior número de interações em cada via. Na tabela 2 são apresentados os nove genes mais expressos (coluna gene) com seu valor de expressão (ME), sua via associada e o seu grau de conectividade (grau). Em seguida foram associados aos genes mais expressos os nós mais conectados em cada via.

Na tabela 2 são apresentados oito genes mais conectados e que têm ligação direta com o gene mais expresso (vizinho), com exceção do gene mais expresso $R A D 50$, que não está interagindo diretamente com o gene mais conectado. Na tabela também podem ser observados os valores da conectividade (grau) e o adenoma associado.

Tabela 2: Genes mais expressos e mais conectados em adenoma.

\begin{tabular}{c|c|c|c|c|c|c}
\hline \multicolumn{4}{c|}{ Genes mais expressos } & \multicolumn{3}{c}{ Genes mais conectados } \\
\hline Gene & MC & Via & Grau & Vizinho & Grau V. & Displasia \\
\hline SKP2 & 1,181 & G1/S & 10 & $C D K N 1 A$ & 14 & cólon \\
CDKN1A & 1,147 & G2/M & 9 & $T P 53$ & 12 & tireoide \\
\hline CHEK1 & 1,195 & RB/E2F & 11 & $C D K 2$ & 21 & cólon \\
\hline$C C N O$ & 1,142 & BER & 3 & $P C N A$ & 23 & cólon \\
\hline NBN & 1,058 & DSBR & 7 & MRE11A & 18 & tireoide \\
\cline { 3 - 6 } XRCC4 & 1,458 & NHEJ & 11 & $X R C C 6$ & 12 & pâncreas \\
\hline$R A D 50$ & 1,066 & NFKB & 3 & - & - & adrenal \\
\hline$A T R$ & 1,103 & SR & 16 & $B R C A 1$ & 29 & adrenal \\
\hline BIRC3 & 1,158 & TNFR1 & 9 & $F A D D$ & 10 & pâncreas \\
\hline
\end{tabular}




\section{CONCLUSÃO}

As análises complementares sobre os genes e interações, realizadas com o auxílio do banco de dados String- $D B$ e com o software Cytoscape, apresentam resultados que descrevem a barreira anti-câncer presente em tecidos de adenoma do cólon, glândula adrenal, pâncreas e foliculares da tireoide. Descrevem também como as proteínas envolvidas nas vias MMG estão associados com a ativação da barreira em tumores malignos.

Como as amostras foram normalizadas pela média robusta para múltiplos chips (RMA), que utiliza o logaritmo na base dois, observou-se que a mudança de expressão diminuiu para os valores experimento versus o seu controle. Mesmo assim, os resultados apresentados mostram a ativação de várias proteínas identificadas nas vias MMG.

Os resultados mostram os principais genes expressos na barreira anti-câncer, com destaque para os genes: CDKN1A, CHEK1, ATR, TP53, MRE11A, XRCC4 e BRCA1, que foram identificados como ativadores da barreira anti-câncer, conforme publicado em 2012 por Simão e colaboradores [10].

Sobre os resultados dos estudos complementares propostos, foram localizados os genes que complementam as análises anteriores. Esses genes são: SKP2, CCNO, FADD, RAD50, NBN, $B I R C 3, C D K 2$ e XRCC6.

Com base na literatura, chegam-se a algumas conclusões importantes para esses genes listados aqui e perspectivas para estudos futuros. Por exemplo, o gene XRCC4, que foi destacado pela sua alta expressão, foi já identificado em estudos onde há supressão devido ao uso da quimioterapia, diminuindo a instabilidade celular [52].

Outro gene destacado pela sua expressão foi o gene $S K P 2$. Em alguns trabalhos há relação da quimioterapia e da radioterapia com a resistência e baixa efetividade nos tratamentos contra $o$ câncer durante a expressão deste gene [28]. Entre os genes destacados pela quantidade de interação está o $F A D D$. Alguns resultados recentes estabelecem um novo mecanismo para a potenciação da atividade de frear a progressão tumoral, unindo a terapia quimioterápica com fármacos que ativam as vias de necroptosis, que estão associadas à morte celular [53].

Ressalta-se que outros genes presentes nas vias modeladas, mesmo que não foram os mais expressos ou com mais interações para entraram no grupo de maior destaque da tabela 2, são também importantes para estudos futuros, como o gene $C C N B 1$, que tem um importante potencial em nanotecnologia, que tem possibilidade de uso como um biomarcador para câncer, podendo ser usado no monitoramento da progressão tumoral [40].

Foi observado que as interações dão suporte aos estudos relacionados a terapias gênicas contra o câncer, como fármacos nanoencapsulados e nanobiossensores. Estas áreas encontramse em ativa exploração e distinção das características moleculares e celulares, que sensibilizam não só o câncer, mas as células alteradas pelos danos no DNA [52].

Portanto, ressalta-se a importância deste trabalho em verificar o envolvimento dos genes conectados através de redes de interação proteica e, com isso, complementar os resultados envolvendo a expressão de proteínas na barreira anti-câncer. A metodologia utilizada e os resultados proporcionam como perspectivas futuras trabalhos complementares a este estudo, com o propósito de contribuir para a terapia do câncer e ajudar no combate de neoplasias que formam os tecidos pré-cancerosos.

\section{AGRADECIMENTOS}

Ao Programa de Pós-graduação em Nanociência do Centro Universitário Francisco, ao orientador deste trabalho, Dr. Éder Maiquel Simão e à CAPES.

\section{REFERÊNCIAS BIBLIOGRÁFICAS}

1. Diestel R. Graph Theory. New York: Springer-Verlag, 2005.

2. Cytoscape Consortium [Internet]. 2014 [atualizado em 10 de abr de 2015; citado em 15 de Jan de 2015] Disponível em: http://www.cytoscape.org.. 
3. Keim, D. Information Visualization and Visual Data Mining, 2002 Ago;7(1):1-8, doi: $10.1109 / 2945.981847$.

4. Shimabukuro M.H. Visualizações Temporais em uma Plataforma de Software Extensível e Adaptável. [Tese], São Carlos (SP): Instituto de Ciências Matemáticas e de Computação - ICMC USP, 2004.

5. Cooper J, Vik JO, Waltemath D. A call for virtual experiments: accelerating the scientific process. Prog in Biop and Mol Biol, 2014 Nov;14:182-5, doi:10.1016/j.pbiomolbio.2014.10.001.

6. Griffiths AJF, Wessler SR, Lewontin RS, Carroll, SB. Introdução à Genética. Rio de Janeiro: Guanabara Koogan, 2008.

7. Alberts B, Johnson A, Lewis J, Raff M, Roberts K, Walter P. Biologia molecular da célula. Porto Alegre: Artmed, 2010.

8. Bohgaki T, Bohgaki M, Hakem R. DNA double-strand break signaling and human disorders. Genome Integrity. 2010 Nov;5;1(1):1-15. doi: 10.1186/2041-9414-1-15.

9. Tomasetti C, Vogelstein B. Variation in cancer risk among tissues can be explained by the number of stem cell divisions. Science. 2015 Jan;347(6217): 78-81, doi: 10.1126/science.1260825

10. Simão EM, Bugs CA, Castro MAA, Sinigaglia M, Librelotto GR, Mombach JCM. Induced Genome Maintenance Pathways in Pre-cancer Tissues Describe an Anti-cancer Barrier in Tumor Development. Mol. BioSyst. 2012 Jun;8(11):3003-9, doi: 10.1039/C2MB25242B.

11. Ludwig JK., Santos CL, Simão EM. Radioterapia de Glioblastoma: Reorganização das Vias de Manutenção do Genoma. Scientia Plena. 2014, Jul;10(070901):1-9.

12. Halazonetis TD, Gorgoulis VG, Bartek J. An Oncogene-Induced DNA Damage Model for Cancer Development, Science, 2008 Mai 319:1352-55, doi: 10.1126/science.1140735.

13. Haase SB, Wittenberg C. Topology and Control of the Cell-Cycle-Regulated Transcriptional Circuitry. Genetics, 2014 Jan;196(1):65-90. doi: 10.1534/genetics.113.152595.

14. Sohrabi N, Valizadeh A, Farkhani SM, Akbarzadeh A. Basics of DNA biosensors and cancer diagnosis. Artificial Cells. Nanomedicine, and Biotechnology. Artif Cells Nanomed Biotechnol. 2014 Nov 13:1-10.

15. Wang L, Meng J, Cao W, Li Q, Qiu Y, Sun B, Li LM. Induction of apoptosis through ER stress and TP53 in MCF-7 cells by the nanoparticle [Gd@C82(OH)22]n: A systems biology study. Methods. 2014 Jun;67(3):394-406. doi: 10.1016/j.ymeth.2014.01.007.

16. Simão EM, Cabral HC, Castro MAA, Sinigaglia M, Mombach JCM, Librelotto GR. Modeling the Human Genome Maintenance Network. Physica A. 2010 Oct;389(19):4188-94. doi: 10.1016/j.physa.2010.05.051

17. GSE4183. Inflammation, adenoma and cancer: objective classification of colon biopsy specimens with gene expression signature [Internet]. GEO, 2007 - [atualizado em 02 de Jul de 2015; citado em 10 de mar de 2015] Disponível em: http://www.ncbi.nlm.nih.gov/geo/query/acc.cgi?acc=GSE4183.

18. GSE10927: Human adrenocortical carcinomas (33), adenomas (22), and normal adrenal cortex (10), on Affymetrix HG_U133_plus_2 arrays [Internet]. GEO, 2011 - [atualizado em 02 de Jul de 2015; citado em 10 de mar de 2015]. Disponível em: http://www.ncbi.nlm.nih.gov/geo/query/acc. cgi?acc=GSE10927.

19. GSE19650: Expression data from epithelial cells during the process of multistep pancreatic carcinogenesis. [Internet]. GEO, 2010 - [atualizado em 02 de Jul de 2015; citado em 11 de mar de 2015]. Disponível em: http://www.ncbi.nlm.nih.gov/geo/query/acc.cgi?acc=GSE19650.

20. GSE27155: Human thyroid adenomas, carcinomas, and normals. [Internet]. GEO, 2011 - [atualizado em 14 de Mai de 2015; citado em 11 de mar de 2015]. Disponível em http://www.ncbi.nlm.nih.gov/geo/query/acc.cgi?acc=GSE27155.

21. Ruiz C, Huang W, Hegi ME, Lange K, Hamou MF, Fluri E, Oakeley, EJ, Chiquet-Ehrismann R, Orend G. Differential Gene Expression Analysis Reveals Activation of Growth Promoting Signaling Pathways by Tenascin-C. Cancer Research. 2004 Oct; 64:7377-83, doi: 10.1158/0008-5472.CAN04-1234

22. Shannon P, Markiel A, Ozier O, Baliga NS, Wang JT, Ramage D, Amin N, Schwikowski B, Ideker T. Cytoscape: A Software Environment for Integrated Models of Biomolecular Interaction Networks. Genome Res. 2003 Nov;13(11):2498-504, doi:10.1101/gr.1239303.

23. Liao YJ, Bai HY, Li ZH, Zou J, Chen JW, Zheng F, Zhang JX, Mai SJ, Zeng MS, Sun HD, Pu JX, Xie D. Longikaurin A, a natural ent-kaurane, induces G2/M phase arrest via downregulation of Skp2 and apoptosis induction through ROS/JNK/c-Jun pathway in hepatocellular carcinoma cells. Cell Death Dis. 2014 Mar;20(5):e1137. doi: 10.1038/cddis.2014.66.

24. Tian K, Rajendran R, Doddananjaiah M, Krstic-Demonacos M, Schwartz JM. Dynamics of DNA Damage Induced Pathways to Cancer. Plos One. 2013 Set;8(9):e72303, doi: 10.1371/journal.pone.0072303. 
25. Tian YF, Chen TJ, Lin CY, Chen LT, Lin LC, Hsing CH, Lee SW, Sheu MJ, Lee HH, Shiue YL, Huang HY, Pan HY, Li CF, Chen SH. SKP2 overexpression is associated with a poor prognosis of rectal cancer treated with chemoradiotherapy and represents a therapeutic target with high potential. Tumour Biol. 2013 Apr;34(2):1107-1, doi: 10.1007/s13277-013-0652-z.

26. Maglott D, Ostell J, Pruitt KD, Tatusova T. Entrez Gene: gene-centered information at NCBI. Nucleic Acids Res. 2011 Jan;39:52-7. doi: 10.1093/nar/gkq1237.

27. Grassilli E, Narloch R, Federzoni E, Ianzano L, Pisano F, Giovannoni R, Romano G, Masiero L, Leone BE, Bonin S, Donada M, Stanta G, Helin K, Lavitrano M. Inhibition of GSK3B bypass drug resistance of p53-null colon carcinomas by enabling necroptosis in response to chemotherapy. Clin Cancer Res. 2013 Jul;19(14):3820-31, doi: 10.1158/1078-0432.CCR-12-3289.

28. Nelson DL, COX MM. Lehninger Principles of Biochemistry. W. H. Freeman; 2004.

29. Nam EA, CORTEZ D. ATR signaling: more than meeting at the fork; Biochem J. 2011 Jun;436(3):527-36, doi: 10.1042/BJ20102162.

30. Koundrioukoff S, Carignon S, Técher H, Letessier A, Brison O, Debatisse M. Stepwise activation of the ATR signaling pathway upon increasing replication stress impacts fragile site integrity. PLoS Genet. 2013;9(7):e1003643. doi: 10.1371/journal.pgen.1003643.

31. Jeong H, Mason SP, Barabási AL, Oltvai ZN. Lethality and centrality in protein networks. Nature, 2001 v. 411:41-42, doi:10.1038/35075138.

32. Bianco S, Jangal M, Garneau D, Gévry N. LRH-1 controls proliferation in breast tumor cells by regulating CDKN1A gene expression. Oncogene. 2014 Dec;1(0). doi: 10.1038/onc.2014.382.

33. Gupta R, Dong Y, Solomon PD, Wettersten HI, Cheng CJ, Min JN, Henson J, Dogra SK, Hwang SH, Hammock BD, Zhu LJ, Reddel RR, Saltzman WM, Weiss RH, Chang S, Green MR, Wajapeyee N. Synergistic tumor suppression by combined inhibition of telomerase and CDKN1A. Proc Natl Acad Sci U S A. 2014 Jul;111(30):3062-71, doi: 10.1073/pnas.1411370111.

34. Hao ZF, Su YM, Wang CM, Yang RY. Activating transcription factor 3 interferes with p21 activation in histone deacetylase inhibitor-induced growth inhibition of epidermoid carcinoma cells. Tumour Biol. 2015 Mar;36(3):1471-6, doi: 10.1007/s13277-014-2618-1.

35. Gamper AM, Rofougaran R, Watkins SC, Greenberger JS, Beumer JH, Bakkenist CJ. ATR kinase activation in G1 phase facilitates the repair of ionizing radiation-induced DNA damage. Nucleic Acids Res. 2013 Dec;41(22):10334-44, doi: 10.1093/nar/gkt833.

36. Ding K, Li W, Zou Z, Zou X, Wang C. CCNB1 is a prognostic biomarker for ER+ breast cancer. Med Hypotheses. 2014 Sep;83(3):359-64, doi: 10.1016/j.mehy.2014.06.013.

37. Murria R, Palanca S, de Juan I, Egoavil C, Alenda C, García-Casado Z, Juan MJ, Sánchez AB, Santaballa A, Chirivella I, Segura Á, Hervás D, Llop M, Barragán E, Bolufer P. Methylation of tumor suppressor genes is related with copy number aberrations in breast cancer. Am J Cancer Res. Am J Cancer Res. 2014 Dec 15;5(1):375-85.

38. Krokan HE, Bjørås M. Base Excision Repair. Cold Spring Harb Perspect Biol. 2013 Apr;5(4):1-23. doi: 10.1101/cshperspect.a012583.

39. Toprani SM, Das B. Role of base excision repair genes and proteins in gamma-irradiated resting human peripheral blood mononuclear cells. Mutagenesis. 2015 Mar;(2):247-61, doi: 10.1093/mutage/geu065.

40. Qi W, Wang R, Chen H, Wang X, Xiao T, Boldogh I, Ba X, Han L4, Zeng X3.BRG1 promotes DNA double-strand break repair by facilitating the replacement of RPA with RAD51. J Cell Sci. 2015 Jan;128(2):317-30, doi: 10.1242/jcs.159103.

41. Long XD, Yao JG, Zeng Z, Ma Y, Huang XY, Wei ZH, Liu M, Zhang JJ, Xue F, Zhai B, Xia Q. Polymorphisms in the coding region of $\mathrm{X}$-ray repair complementing group 4 and aflatoxin B1-related hepatocellular carcinoma. Hepatology. 2013 Jul;58(1):171-81. doi: 10.1002/hep.26311.

42. Liu C, Srihari S, Cao KA, Chenevix-Trench G, Simpson PT, Ragan MA, Khanna KK. A fine-scale dissection of the DNA double-strand break repair machinery and its implications for breast cancer therapy. Nucleic Acids Res. 2014 Jun;42(10):6106-27, doi: 10.1093/nar/gku284.

43. Luo K, Zhang H, Wang L, Yuan J, Lou Z. Sumoylation of MDC1 is important for proper DNA damage response. EMBO J. 2012 Jun;31(13):3008-19, doi: 10.1038/emboj.2012.158.

44. Yamamoto Y, Miyamoto M, Tatsuda D, Kubo M, Nakagama H, Nakamura Y, Satoh H, Matsuda K, Watanabe T, Ohta T. A rare polymorphic variant of NBS1 reduces DNA repair activity and elevates chromosomal instability. Cancer Res. 2014 Jul;74(14):3707-15, doi: 10.1158/0008-5472.CAN-133037.

45. Liu L, Jiao J, Wang Y, Zhang D, Wu J, Huang D. Lack of association of the TP53BP1 Glu353Asp polymorphism with risk of cancer: a systematic review and meta-analysis. PLoS One. 2014 Mar 6;9(3):1-9, doi: 10.1371/journal.pone.0090931. 
46. Arcas A, Fernández-Capetillo O, Cases I, Rojas AM. Emergence and evolutionary analysis of the human DDR network: implications in comparative genomics and downstream analyses. Mol Biol Evol. 2014 Apr;31(4):940-61, doi: 10.1093/molbev/msu046.

47. Terasawa M, Shinohara A, Shinohara M. Canonical non-homologous end joining in mitosis induces genome instability and is suppressed by M-phase-specific phosphorylation of XRCC4. PLoS Genet. 2014 Aug 28;10(8):1-15, doi: 10.1371/journal.pgen.1004563.

48. Jung SA, Park YM, Hong SW, Moon JH, Shin JS, Lee HR, Ha SH, Lee DH, Kim JH, Kim SM, Kim JE, Kim KP, Hong YS, Choi EK, Lee JS, Jin DH, Kim T. cIAP1 stability contributes to YM155 resistance in human gastric cancer cells. J Biol Chem. 2015 Apr;290(16):9974-85, doi: 10.1074/jbc.M114.600874.

49. Calandria JM, Asatryan A, Balaszczuk V, Knott EJ, Jun BK, Mukherjee PK, Belayev L, Bazan NG NPD1-mediated stereoselective regulation of BIRC3 expression through cREL is decisive for neural cell survival. Cell Death Differ. 2015 Aug;22(8):1363-77, doi: 10.1038/cdd.2014.233.

50. Kishore R, Tkebuchava T, Sasi SP, Silver M, Gilbert HY, Yoon YS, Park HY, Thorne T, Losordo DW, Goukassian DA. Tumor Necrosis Factor- $\alpha$ Signaling via TNFR1/p55 Is Deleterious Whereas TNFR2/p75 Signaling Is Protective in Adult Infarct Myocardium. Advances in TNF Family Research. Adv Exp Med Biol. 2011;691:433-48, doi: 10.1007/978-1-4419-6612-4_45.

51. Brown MF, Leibowitz BJ, Chen D, He K, Zou F, Sobol RW, Beer-Stolz D, Zhang L, Yu J. Loss of Caspase-3 sensitizes colon cancer cells to genotoxic stress via RIP1-dependent necrosis. Cell Death Dis. 2015 Apr;6:1-10. doi: 10.1038/cddis.2015.104.

52. Bohunicky B, Mousa S. A. Biosensors: the new wave in cancer diagnosis. Nanotechnol Sci Appl. 2010 Dec;2011(4):1-10, doi: http://dx.doi.org/10.2147/NSA.S13465.

53. Qureshia A, Kangb WP, Davidsonb JL, Gurbuz Y. Review on carbon-derived, solid-state, micro and nano sensors for electrochemical sensing applications. Diamond \& Related Materials. 2009 Dec;18: 1401-1420, doi:10.1016/j.diamond.2009.09.008. 